\title{
Joint Effect of Anogessius Leocarpus Gum (AL Gum) Exudate and Halide Ions on the Corrosion of Mild Steel in 0.1 M HCl
}

\author{
Paul O. Ameh, ${ }^{a}$ Anduang O. Odiongenyi ${ }^{b}$ and Nnabuk O. Eddy ${ }^{a, b, *}$ \\ ${ }^{a}$ Department of Chemistry, Ahmadu Bello University, Zaria, Nigeria \\ ${ }^{b}$ Department of Chemistry, Akwa Ibom State University, Ikot Akpaeden, \\ P. M. B. 1167, Uyo, Akwa Ibom State, Nigeria
}

Received 2 May 2012; accepted 31 August 2012

\begin{abstract}
In an attempt to improve the corrosion inhibition potential of Anogessius leocarpus gum exudates for mild steel in solutions of $\mathrm{HCl}$, corrosion inhibition efficiencies of the gum, $\mathrm{KI}, \mathrm{KCl}$, and $\mathrm{KBr}$ were determined experimentally using weight loss and gasometric methods. $0.05 \mathrm{M} \mathrm{KI}, 0.05 \mathrm{M} \mathrm{KBr}$ and $0.05 \mathrm{M} \mathrm{KCl}$ were combined with various concentrations of Anogessius leocarpus gum and their combined inhibition efficiencies were used in computing synergistic parameters for the respective combinations. The results obtained indicated that combination of 0.4 and $0.5 \mathrm{~g} / \mathrm{L}$ of $\mathrm{AL}$ gum with $0.05 \mathrm{M}$ solutions of $\mathrm{KI}$ and $\mathrm{KBr}$, respectively, enhanced inhibition efficiency of the gum. However, for all concentrations of $\mathrm{AL}$ gum, combinations with $0.05 \mathrm{M} \mathrm{KCl}$ recorded a remarkable increase in inhibition efficiency, but calculated values of the synergistic parameter indicated that the adsorption of AL gum on mild steel surface is antagonized by the presence of $\mathrm{Cl}^{-}$. Theory of competitive and co-operative adsorption has been used to explain the co-adsorption of the gum and the halides. From calculated values of activation energy $(<80 \mathrm{~kJ} / \mathrm{mol})$, free energy of adsorption $(<-40 \mathrm{~kJ} / \mathrm{mol})$ and the variation of inhibition efficiency with temperature, the adsorption characteristics of the gum, halides and that of gum-halide mixtures were found to be consistent with the mechanism of physical adsorption. The adsorption was also found to be endothermic, spontaneous and favored the Langmuir adsorption model.
\end{abstract}

Keywords: corrosion, inhibition, adsorption, Anogessius leocarpus gum, synergism, potassium halides.

\section{Introduction}

Corrosion is the deterioration of materials by chemical interaction with their environment. The consequences of corrosion are many and varied and its effects on the safe, reliable and efficient operation of equipment or structures are severe.

\footnotetext{
* Corresponding author. E-mail: nabukeddy@yahoo.com
} 
Most corrosion inhibitors are synthetic chemicals that are expensive and hazardous to the environment [1]. The use of natural products (green corrosion inhibitors) has been given extensive research interest because most of them are easily available, less expensive, less toxic and biodegradable [2-14]. In our research group, we have found that some natural polymers are effective corrosion inhibitors and can compete with green corrosion inhibitors [15]. According to Eddy et al. [15], polymers are effective corrosion inhibitors because through their functional groups they form complexes with metal ions and on the metal surface. These complexes occupy a large surface area that can blanket the metal surface and protect it against corrosion [16-17].

In spite of their numerous advantages as corrosion inhibitors, some natural polymers are found to be characterized with low values of inhibition efficiency. Therefore, it could be beneficial to work out efforts that can be adopted to improve upon their inhibition potentials. One of the ways of achieving this is through synergism [18]. Synergism has become one of the most important effects in inhibition processes and serves as the basis for all modern corrosion inhibitor formulations. It is an effective method to improve the inhibitive performance, to decrease the amount of usage, and to diversify the application of the inhibitor in acidic media [19]. Eddy et al. [3,20] stated that addition of $\mathrm{Br}^{-}$ and $\mathrm{I}^{-}$ions to Lasianthera Africana and Gnetum African leaves extract antagonized their inhibition potentials for mild steel in solutions of $\mathrm{H}_{2} \mathrm{SO}_{4}$, while $\mathrm{Cl}^{-}$exerted synergistic effect in the same media. Synergistic inhibition effect between iodide ion and natural exudate gums of Raphia hookeri [20] and Pachylobus edulis [21] for mild steel in acidic media has been reported. In view of the high favourable composition of Anogessius leocarpus gum exudates and their low corrosion inhibition potential [15], the objective of the present study is to investigate the effect of halide ions ( $\mathrm{KI}, \mathrm{KCl}$ and $\mathrm{KBr}$ ) on the enhancement of the corrosion inhibition potential of Anogessius leocarpus gum exudates.

\section{Materials and methods \\ Materials}

Materials used for this study were mild steel sheets of composition (wt \%, as determined by quantiometric method): Mn (0.6), P (0.36), C (0.15), Si (0.03) and Fe (99.01). The sheets were mechanically cut into different coupons, each of dimensions $5 \times 4 \times 0.11 \mathrm{~cm}$. Each coupon was degreased by washing with ethanol, cleaned with acetone and allowed to dry in the air before preservation in a desiccator. All reagents used for the study were analar grade and double distilled water was used in preparing the required solutions. The Anogessus leocarpus gum exudates used for the studies were obtained from the Anogessius leocarpus tree, purified and concentrated using the method reported in our last work [15].

\section{Weight loss measurement}

In the gravimetric experiment, a previously weighed metal (mild steel) coupon was completely immersed in $250 \mathrm{~mL}$ of the test solution in an open beaker. The 
beaker was covered with aluminium foil and inserted into a water bath maintained at $303 \mathrm{~K}$. After every 24 hours, in order to remove the corrosion product, each coupon was withdrawn and washed with a solution containing 50 $\% \mathrm{NaOH}$ and $100 \mathrm{~g} \mathrm{~L}^{-1}$ of zinc dust. The washed coupon was rinsed in acetone and dried in the air before re-weighing. The experiment was repeated at $333 \mathrm{~K}$. In each case, the difference in weight for a period of 168 hours was taken as the total weight loss. From the average weight loss (mean of three replicate analysis) results, the inhibition efficiency $(\% \mathrm{I})$ of the inhibitor, the degree of surface coverage $(\theta)$ and the corrosion rate of mild steel (CR) were calculated using equations 1,2 and 3 , respectively,

$$
\begin{aligned}
& \% \mathrm{I}=\left[1-\left(\mathrm{W}_{1} / \mathrm{W}_{2}\right)\right] \times 100 \\
& \theta=\left(1-\mathrm{W}_{1} / \mathrm{W}_{2}\right) \\
& \mathrm{CR}=\left(\mathrm{W}_{1}-\mathrm{W}_{2}\right) / \mathrm{At}
\end{aligned}
$$

where CR is the corrosion rate of mild steel in $\mathrm{g} / \mathrm{cm}^{2} / \mathrm{h}, \mathrm{W}_{1}$ and $\mathrm{W}_{2}$ are the weight losses ( $\mathrm{g}$ ) for mild steel in the absence and presence of the inhibitor, $\theta$ is the degree of surface coverage of the inhibitor, $A$ is the area of the mild steel coupon (in $\mathrm{cm}^{2}$ ), $\mathrm{t}$ is the period of immersion (in hours).

\section{Results and discussion}

\section{Effect of AL gum and halides}

Fig. 1 shows the variation of weight loss with time for the corrosion of mild steel in various concentrations of $\mathrm{HCl}$ at $303 \mathrm{~K}$. The figure indicates that the rate of corrosion of mild steel in $\mathrm{HCl}$ increases with increase in concentration. The corrosion rate of mild steel in solutions of $\mathrm{HCl}$ was also found to increase with increase in temperature (figure not shown). Fig. 2 shows the variation of weight loss of mild steel in solution of $\mathrm{HCl}$ containing various concentrations of $\mathrm{AL}$ gum as an additive at $303 \mathrm{~K}$. The figure depicts that weight loss of mild steel in the blank is higher than those measured for solutions of $\mathrm{HCl}$ containing various concentrations of $\mathrm{AL}$ gum. This indicates that $\mathrm{AL}$ gum retarded the rate of corrosion of mild steel in solutions of $\mathrm{HCl}$ and that $\mathrm{AL}$ gum is an inhibitor for the corrosion of mild steel in solutions of $\mathrm{HCl}$. At higher temperature $(333 \mathrm{~K})$, weight loss of mild steel in solution of $\mathrm{HCl}$ was found to follow similar pattern. However, at higher temperature $(333 \mathrm{~K})$, measured values of weight loss were higher than those obtained at a lower temperature $(303 \mathrm{~K})$. From the calculated values of corrosion rate of mild steel and of the inhibition efficiency of AL gum (Table 1), it can be seen that the inhibition efficiency of AL gum for mild steel in solutions of $\mathrm{HCl}$ increases with increase in the concentration of the inhibitor, but decreases with increasing temperature, indicating that AL gum is an adsorption inhibitor for the corrosion of mild steel in solutions of $\mathrm{HCl}$ and that the adsorption of AL gum favours the mechanism of physical adsorption. 


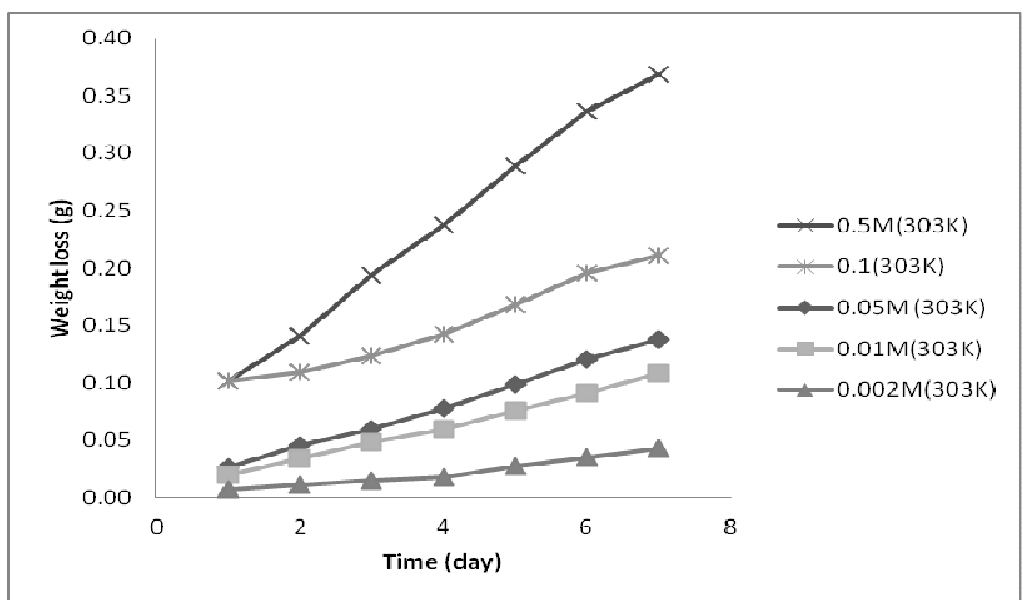

Figure 1. Variation of weight loss with time for the corrosion of mild steel in various concentrations of $\mathrm{HCl}$.

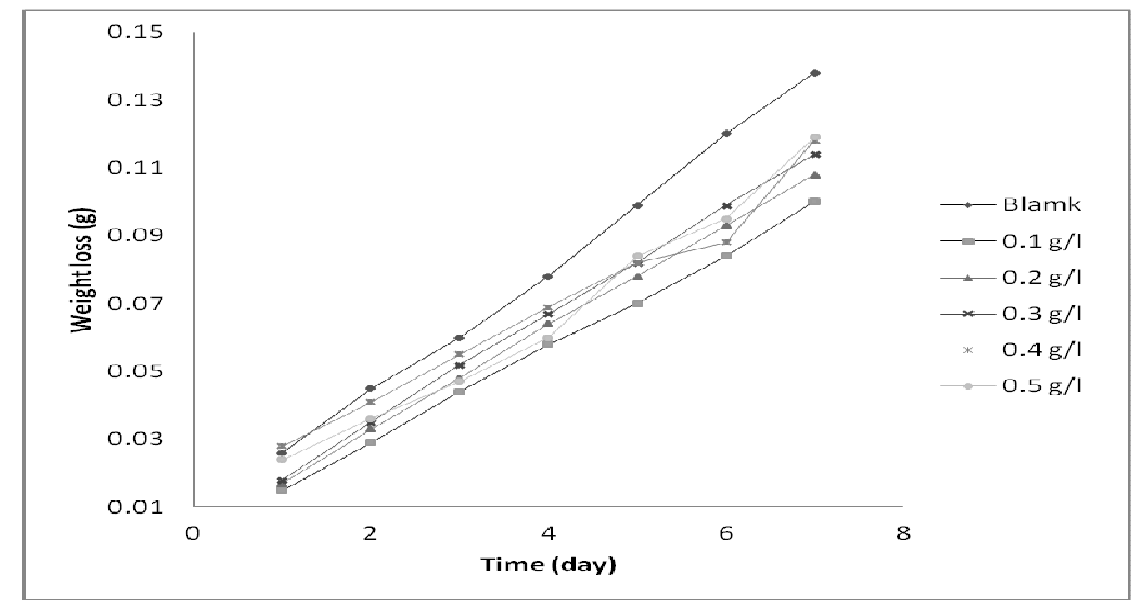

Figure 2. Variation of weight loss with time for the corrosion of mild steel in $0.05 \mathrm{M}$ $\mathrm{HCl}$ containing various concentrations of AL gum at $303 \mathrm{~K}$.

Calculated values of inhibition efficiency for AL gum are relatively low when compared to those obtained for some good green corrosion inhibitors. Therefore, in order to enhance the inhibition potential of $\mathrm{AL}$ gum for mild steel in solutions of $\mathrm{HCl}$, synergistic effects of $\mathrm{AL}$ gum and halides ( $\mathrm{KI}, \mathrm{KBr}$ and $\mathrm{KCl}$ ) were studied. Fixed concentration of the halides $(0.005 \mathrm{M})$ in combination with various concentrations of $\mathrm{Al}$ gum was used for synergistic studies. According to Eddy et al. [19], synergism occurs when the combined inhibition efficiency of two or more inhibitors is greater than the sum of the inhibition efficiencies of the individual inhibitors, and that synergism of the corrosion inhibitor is due to the interaction between the components of the inhibitors, or the inhibitor and one of the ions present in aqueous solution. Table 2 presents values of the corrosion rate of mild steel and of the inhibition efficiency of various concentrations of KI, $\mathrm{KBr}, \mathrm{KCl}, \mathrm{Al}$ gum in combination with halides. From the results obtained, it is evident that there is a significant enhancement of the inhibition efficiency of AL gum by potassium halides. Synergistic combination of AL gum with $0.005 \mathrm{M}$ $\mathrm{KCl}, 0.005 \mathrm{M} \mathrm{KBr}$ and $0.005 \mathrm{M} \mathrm{KI}$ is found to increase the inhibition efficiency of AL gum, indicating that these halides have the potential of modifying the adsorption of AL gum on mild steel surface. In Fig. 3, plots showing the 
variation of the inhibition efficiencies of AL gum and those of halides and ALhalides mixtures with concentration of AL gum are presented. From the figure, it is significant to note that inhibition efficiencies of the respective AL-halide mixture are higher than those of the corresponding halides and that of AL-gum. From the plots, it is evident that the increase in inhibition efficiency of AL gum as due to interaction with potassium halides is consistent with the following trend, $\mathrm{KI}>\mathrm{KBr}>\mathrm{KCl}$.

In order to ascertain synergistic, antagonistic and non effect of halides on the adsorption of AL gum, synergistic parameters, $\mathrm{S}$, were calculated for various combinations of the inhibitor and fixed concentrations of the halides $(\mathrm{KI}, \mathrm{KCl}$ and $\mathrm{KBr}$ ) using the following equation [19],

$$
S=\frac{1-I_{A}-I_{B}+I_{A} I_{B}}{1-I_{A B}}
$$

where $I_{A}$ and $I_{B}$ are inhibition efficiencies of compound $A$ and $B$, respectively, and $\mathrm{I}_{\mathrm{AB}}$ is the inhibition efficiency of a combination of the two inhibitors. Calculated values of $\mathrm{S}$ are presented in Table 2.

The results indicate that the synergistic parameters for combinations of various concentrations of AL gum with $0.005 \mathrm{M} \mathrm{KI}, 0.005 \mathrm{M} \mathrm{KBr}$ and $0.005 \mathrm{M} \mathrm{KCl}$ tend to increase with increase in the concentration of AL gum, as shown in Fig. 4. Consequently, calculated values of the synergistic parameters were greater than unity at $\mathrm{AL}$ concentration of $0.5 \mathrm{~g} / \mathrm{L}$ when the inhibitor was co-employed with $0.005 \mathrm{M} \mathrm{KI}$ and $\mathrm{KBr}$, respectively. Also $\mathrm{S}$ values calculated for combination of 0.4 and $0.5 \mathrm{~g} / \mathrm{L}$ of $\mathrm{AL}$ gum inhibitor and $0.005 \mathrm{M} \mathrm{KI}$ were greater than unity. Therefore, at these concentrations, adsorption of AL gum on mild steel surface is enhanced by synergistic combination of $\mathrm{KI}$ and $\mathrm{KBr}$ at concentrations $\geq 0.4 \mathrm{~g} / \mathrm{L}$ and $\geq 0.5 \mathrm{~g} / \mathrm{L}$, respectively. Below these critical concentrations and for all concentrations of $\mathrm{Al}$ gum in combination with $\mathrm{KCl}$, calculated values of the synergistic parameter were less than unity, indicating that the adsorption of AL gum on mild steel is antagonized by the presence of $\mathrm{KCl}$. The synergistic effect observed for iodide and bromide ions may be due to co-adsorption of iodide or bromide with the inhibitors' cations. It has been found that co-adsorption can be either competitive (in which the anion and the cation are adsorbed at different sites on the metal) or co-operative adsorption, in which the anion is chemisorbed on the surface of the metal and the cation on the layer of the anion [23]. However, it is possible to have both types of adsorption. 


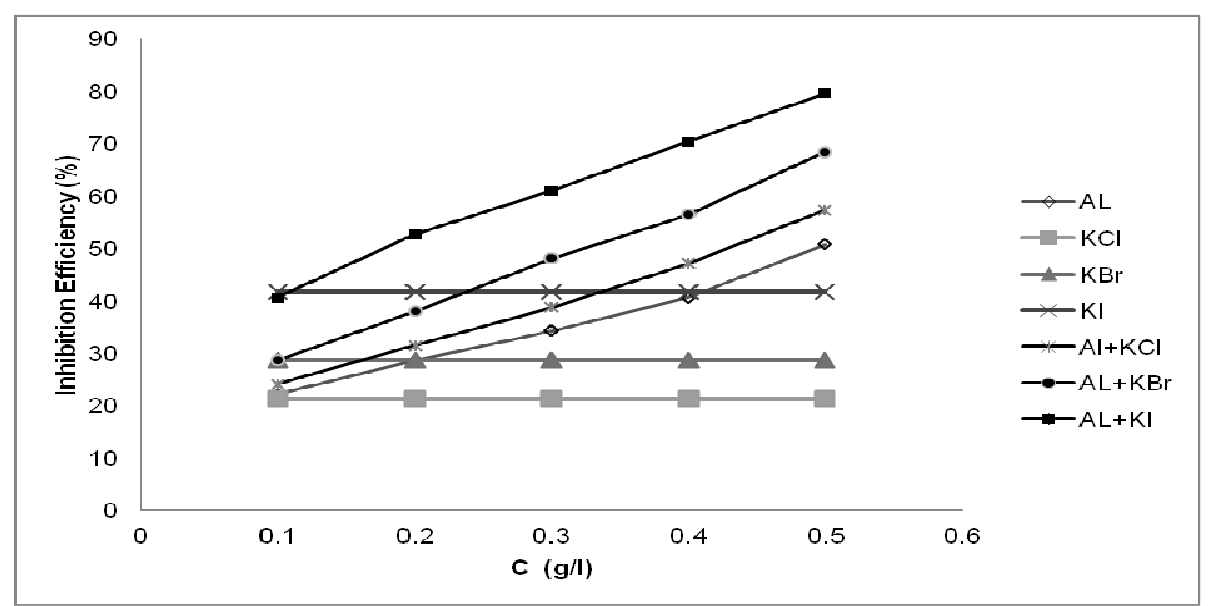

Figure 3. Variation of the inhibition efficiencies of AL gum, AL-halides combinations and halides with concentration at $303 \mathrm{~K}$.

Table 1. Inhibition efficiency of AL gum and corrosion rates of mild steel in various media.

\begin{tabular}{|c|c|c|c|c|c|c|}
\hline System & $\begin{array}{c}\% \mathrm{I} \text { at } \\
303 \mathrm{~K}\end{array}$ & $\begin{array}{c}\% \text { I at } \\
333 \mathrm{~K}\end{array}$ & $\theta_{2}$ & $\theta_{1}$ & $\begin{array}{c}\mathrm{CR}_{1} \\
\left(\mathrm{~g} / \mathrm{cm}^{2} \mathrm{~h}\right)\end{array}$ & $\begin{array}{c}\mathrm{CR}_{2} \\
\left(\mathrm{~g} / \mathrm{cm}^{2} \mathrm{~h}\right)\end{array}$ \\
\hline $0.05 \mathrm{M} \mathrm{KCl}$ & 21.3 & 18.6 & 0.21 & 0.19 & $7.5 \times 10^{-3}$ & $1.0 \times 10^{-2}$ \\
\hline $0.05 \mathrm{M} \mathrm{KBr}$ & 28.7 & 24.3 & 0.29 & 0.24 & $6.8 \times 10^{-3}$ & $9.4 \times 10^{-3}$ \\
\hline $0.05 \mathrm{M} \mathrm{KI}$ & 41.7 & 36.4 & 0.42 & 0.36 & $5.6 \times 10^{-3}$ & $7.9 \times 10^{-3}$ \\
\hline $0.5 \mathrm{~g} / \mathrm{L} \mathrm{AL}$ & 50.9 & 40.0 & 0.51 & 0.40 & $4.7 \times 10^{-3}$ & $7.5 \times 10^{-3}$ \\
\hline $0.4 \mathrm{~g} / \mathrm{L} \mathrm{AL}$ & 40.7 & 32.1 & 0.41 & 0.32 & $5.7 \times 10^{-3}$ & $8.4 \times 10^{-3}$ \\
\hline $0.3 \mathrm{~g} / \mathrm{L} \mathrm{AL}$ & 34.3 & 28.6 & 0.34 & 0.29 & $6.3 \times 10^{-3}$ & $8.9 \times 10^{-3}$ \\
\hline $0.2 \mathrm{~g} / \mathrm{L} \mathrm{AL}$ & 28.7 & 22.9 & 0.29 & 0.23 & $6.8 \times 10^{-3}$ & $9.6 \times 10^{-3}$ \\
\hline $0.1 \mathrm{~g} / \mathrm{L} \mathrm{AL}$ & 22.2 & 18.6 & 0.22 & 0.19 & $7.5 \times 10^{-3}$ & $1.0 \times 10^{-2}$ \\
\hline $0.5 \mathrm{~g} / \mathrm{L} \mathrm{AL}+0.05 \mathrm{M} \mathrm{KCl}$ & 57.4 & 48.6 & 0.57 & 0.49 & $4.1 \times 10^{-3}$ & $6.4 \times 10^{-3}$ \\
\hline $0.4 \mathrm{~g} / \mathrm{L} \mathrm{AL}+0.05 \mathrm{M} \mathrm{KCl}$ & 47.2 & 40.0 & 0.47 & 0.40 & $5.1 \times 10^{-3}$ & $7.5 \times 10^{-3}$ \\
\hline $0.3 \mathrm{~g} / \mathrm{L} \mathrm{AL}+0.05 \mathrm{M} \mathrm{KCl}$ & 38.8 & 32.1 & 0.39 & 0.32 & $5.9 \times 10^{-3}$ & $8.4 \times 10^{-3}$ \\
\hline $0.2 \mathrm{~g} / \mathrm{L} \mathrm{AL}+0.05 \mathrm{M} \mathrm{KCl}$ & 31.5 & 26.4 & 0.32 & 0.26 & $6.6 \times 10^{-3}$ & $9.1 \times 10^{-3}$ \\
\hline $0.1 \mathrm{~g} / \mathrm{L} \mathrm{AL}+0.05 \mathrm{M} \mathrm{KCl}$ & 24.1 & 20.0 & 0.24 & 0.20 & $7.3 \times 10^{-3}$ & $9.9 \times 10^{-3}$ \\
\hline $0.5 \mathrm{~g} / \mathrm{L} \mathrm{AL}+0.05 \mathrm{M} \mathrm{KBr}$ & 68.5 & 60.7 & 0.69 & 0.61 & $3.0 \times 10^{-3}$ & $4.9 \times 10^{-3}$ \\
\hline $0.4 \mathrm{~g} / \mathrm{L} \mathrm{AL}+0.05 \mathrm{M} \mathrm{KBr}$ & 56.5 & 47.1 & 0.56 & 0.47 & $4.2 \times 10^{-3}$ & $6.6 \times 10^{-3}$ \\
\hline $0.3 \mathrm{~g} / \mathrm{L} \mathrm{AL}+0.05 \mathrm{M} \mathrm{KBr}$ & 48.1 & 40.0 & 0.49 & 0.40 & $5.0 \times 10^{-3}$ & $7.5 \times 10^{-3}$ \\
\hline $0.2 \mathrm{~g} / \mathrm{L} \mathrm{AL}+0.05 \mathrm{M} \mathrm{KBr}$ & 38.0 & 31.4 & 0.38 & 0.31 & $5.9 \times 10^{-3}$ & $8.5 \times 10^{-3}$ \\
\hline $0.1 \mathrm{~g} / \mathrm{L} \mathrm{AL}+0.05 \mathrm{M} \mathrm{KBr}$ & 28.7 & 24.3 & 0.29 & 0.24 & $6.8 \times 10^{-3}$ & $9.4 \times 10^{-3}$ \\
\hline $0.5 \mathrm{~g} / \mathrm{L} \mathrm{AL}+0.05 \mathrm{M} \mathrm{KI}$ & 79.6 & 75.7 & 0.80 & 0.76 & $2.0 \times 10^{-3}$ & $3.0 \times 10^{-3}$ \\
\hline $0.4 \mathrm{~g} / \mathrm{L} \mathrm{AL}+0.05 \mathrm{M} \mathrm{KI}$ & 70.4 & 62.8 & 0.70 & 0.63 & $2.9 \times 10^{-3}$ & $4.6 \times 10^{-3}$ \\
\hline $0.3 \mathrm{~g} / \mathrm{L} \mathrm{AL}+0.05 \mathrm{M} \mathrm{KI}$ & 61.1 & 52.9 & 0.61 & 0.53 & $3.7 \times 10^{-3}$ & $5.9 \times 10^{-3}$ \\
\hline $0.2 \mathrm{~g} / \mathrm{L} \mathrm{AL}+0.05 \mathrm{M} \mathrm{KI}$ & 52.7 & 43.6 & 0.53 & 0.44 & $4.5 \times 10^{-3}$ & $7.0 \times 10^{-3}$ \\
\hline $0.1 \mathrm{~g} / \mathrm{L} \mathrm{AL}+0.05 \mathrm{M} \mathrm{KI}$ & 40.7 & 32.9 & 0.41 & 0.33 & $5.7 \times 10^{-3}$ & $8.3 \times 10^{-3}$ \\
\hline
\end{tabular}


Table 2. Synergistic parameters for combination of $0.005 \mathrm{M} \mathrm{KI}, \mathrm{KCl}$ and $\mathrm{KBr}$ with various concentrations of AL gum.

\begin{tabular}{ccccccc}
\hline & \multicolumn{2}{l}{$\mathbf{A L}+\mathbf{K C l}$} & \multicolumn{2}{c}{$\mathbf{A L}+\mathbf{K B r}$} & \multicolumn{2}{c}{$\mathbf{A L}+\mathbf{K I}$} \\
\cline { 2 - 7 } $\mathbf{C}(\mathbf{g} / \mathbf{L})$ & $303 \mathrm{~K}$ & $333 \mathrm{~K}$ & $303 \mathrm{~K}$ & $333 \mathrm{~K}$ & $303 \mathrm{~K}$ & $333 \mathrm{~K}$ \\
0.5 & 0.91 & 0.95 & 1.11 & 1.09 & 1.40 & 1.57 \\
0.4 & 0.88 & 0.92 & 0.97 & 0.92 & 1.17 & 1.16 \\
0.3 & 0.84 & 0.86 & 0.90 & 0.85 & 0.98 & 0.96 \\
0.2 & 0.82 & 0.85 & 0.82 & 0.80 & 0.88 & 0.87 \\
0.1 & 0.81 & 0.83 & 0.77 & 0.77 & 0.76 & 0.77 \\
\hline
\end{tabular}

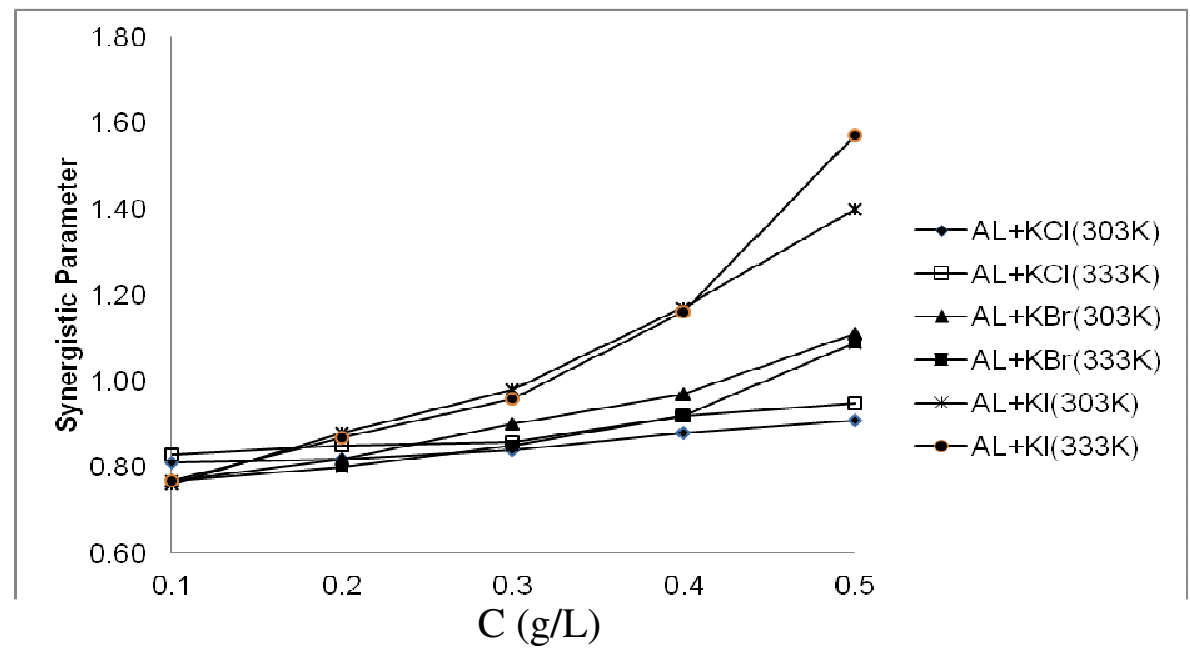

Figure 4. Variation of the synergistic parameter with concentration for joint combinations of AL gum with $0.005 \mathrm{M} \mathrm{KI}, \mathrm{KBr}$ and $\mathrm{KCl}$, at $303 \mathrm{~K}$.

\section{Effect of temperature}

The effect of temperature on the corrosion of mild steel in solutions of $\mathrm{HCl}$ containing various concentrations of $\mathrm{AL}$ was studied using the Arrhenius equation, which can be written as follows [24]:

$$
C R=A \exp \left(\frac{-E_{a}}{R T}\right)
$$

where $\mathrm{CR}$ is the corrosion rate of mild steel in a given medium, $\mathrm{A}$ is the Arrhenius or pre-exponential factor, $E_{a}$ is the activation energy, $R$ is the gas constant and $\mathrm{T}$ is the temperature. If the corrosion rates of mild steel at two temperatures $\left[\mathrm{T}_{1}(303 \mathrm{~K})\right.$ and $\mathrm{T}_{2}(333 \mathrm{~K})$ ] are assumed to be $\mathrm{CR}_{1}$ and $\mathrm{CR}_{2}$, respectively, then equation 5 can be simplified and written as follows,

$$
\frac{C R_{2}}{C R_{1}}=\frac{E_{a}}{2.303 R}\left(\frac{1}{T_{1}}-\frac{1}{T_{2}}\right)
$$

The activation energies calculated from equation 6 are presented in Table 3 . From the results obtained, it can be seen that the activation energies are less than the threshold value required for chemical adsorption $(80 \mathrm{~kJ} / \mathrm{mol})$, indicating that the adsorption of AL gum and those of AL gum-halides mixtures are consistent with the mechanism of charge transfer from the charged inhibitor to the charged 
metal surface, which indicates physisorption. The results also revealed that there is an improvement in the adsorption of AL gum due to synergism, which was observed for the following systems: $0.5 \mathrm{~g} / \mathrm{L} \mathrm{AL}+0.05 \mathrm{M} \mathrm{KI}, 0.5 \mathrm{~g} / \mathrm{L} \mathrm{AL}+0.05$ $\mathrm{M} \mathrm{KI}$ and $0.05 \mathrm{M} \mathrm{KBr}+0.5 \mathrm{~g} / \mathrm{L} \mathrm{KBr}$. This also implies that at higher concentration of AL gum, enhancement of inhibition efficiency through synergistic combinations with $\mathrm{KI}$ or $\mathrm{KBr}$ can be achieved through improved adsorption.

Table 3. Activation energy and heat of adsorption of AL gum and combinations of AL gum with halides on mild steel surface.

\begin{tabular}{ccc}
\hline System & Ea $(\mathrm{kJ} / \mathrm{mol})$ & Qads $(\mathrm{kJ} / \mathrm{mol})$ \\
\hline Blank & 10.92 & - \\
$0.05 \mathrm{M} \mathrm{KCl}$ & 8.55 & 2.67 \\
$0.05 \mathrm{M} \mathrm{KBr}$ & 9.07 & 5.40 \\
$0.05 \mathrm{M} \mathrm{KI}$ & 9.63 & 5.30 \\
$0.5 \mathrm{~g} / \mathrm{L} \mathrm{AL}$ & 13.08 & 9.34 \\
$0.4 \mathrm{~g} / \mathrm{L} \mathrm{AL}$ & 10.86 & 8.18 \\
$0.3 \mathrm{~g} / \mathrm{L} \mathrm{AL}$ & 9.67 & 4.87 \\
$0.2 \mathrm{~g} / \mathrm{L} \mathrm{AL}$ & 9.65 & 6.56 \\
$0.1 \mathrm{~g} / \mathrm{L} \mathrm{AL}$ & 8.05 & 3.87 \\
$0.5 \mathrm{~g} / \mathrm{L} \mathrm{AL}+0.05 \mathrm{M} \mathrm{KCl}$ & 12.47 & 6.75 \\
$0.4 \mathrm{~g} / \mathrm{L} \mathrm{AL}+0.05 \mathrm{M} \mathrm{KCl}$ & 10.80 & 5.98 \\
$0.3 \mathrm{~g} / \mathrm{L} \mathrm{AL}+0.05 \mathrm{M} \mathrm{KCl}$ & 9.89 & 6.43 \\
$0.2 \mathrm{~g} / \mathrm{L} \mathrm{AL}+0.05 \mathrm{M} \mathrm{KCl}$ & 8.99 & 6.13 \\
$0.1 \mathrm{~g} / \mathrm{L} \mathrm{AL}+0.05 \mathrm{M} \mathrm{KCl}$ & 8.53 & 4.90 \\
$0.5 \mathrm{~g} / \mathrm{L} \mathrm{AL}+0.05 \mathrm{M} \mathrm{KBr}$ & 13.74 & 7.40 \\
$0.4 \mathrm{~g} / \mathrm{L} \mathrm{AL}+0.05 \mathrm{M} \mathrm{KBr}$ & 12.65 & 7.58 \\
$0.3 \mathrm{~g} / \mathrm{L} \mathrm{AL}+0.05 \mathrm{M} \mathrm{KBr}$ & 11.35 & 7.67 \\
$0.2 \mathrm{~g} / \mathrm{L} \mathrm{AL}+0.05 \mathrm{M} \mathrm{KBr}$ & 10.22 & 6.51 \\
$0.1 \mathrm{~g} / \mathrm{L} \mathrm{AL}+0.05 \mathrm{M} \mathrm{KBr}$ & 9.36 & 5.40 \\
$0.5 \mathrm{~g} / \mathrm{L} \mathrm{AL}+0.05 \mathrm{M} \mathrm{KI}$ & 11.35 & 4.90 \\
$0.4 \mathrm{~g} / \mathrm{L} \mathrm{AL}+0.05 \mathrm{M} \mathrm{KI}$ & 12.92 & 6.61 \\
$0.3 \mathrm{~g} / \mathrm{L} \mathrm{AL}+0.05 \mathrm{M} \mathrm{KI}$ & 13.06 & 6.86 \\
$0.2 \mathrm{~g} / \mathrm{L} \mathrm{AL}+0.05 \mathrm{M} \mathrm{KI}$ & 12.37 & 7.58 \\
$0.1 \mathrm{~g} / \mathrm{L} \mathrm{AL}+0.05 \mathrm{M} \mathrm{KI}$ & 10.52 & 7.22 \\
\hline & & \\
\hline
\end{tabular}

\section{Heat of adsorption}

The heat of adsorption of AL gum and for various combinations of AL gum with halides were estimated using the following equation [15],

$$
Q_{\text {ads }}=2.303 R\left(\frac{\log \theta_{2}}{1-\theta_{2}}-\frac{\log \theta_{1}}{1-\theta_{1}}\right) \times \frac{T_{2} T_{1}}{T_{2}-T_{1}}
$$


where $Q_{a d s}$ is the heat of adsorption, $R$ is the gas constant, $\theta_{1}$ and $\theta_{2}$ are the degrees of surface coverage for the inhibitor or inhibitor-halide combination at the temperatures $\mathrm{T}_{1}(303 \mathrm{~K})$ and $\mathrm{T}_{2}(333 \mathrm{~K})$, respectively. Values of $\mathrm{Q}_{\mathrm{ads}}$ calculated from equation 8 are also recorded in Table 3 . The results obtained indicate that the adsorption of $\mathrm{AL}$ gum, $\mathrm{KI}, \mathrm{KBr}, \mathrm{KI}$, as well as joint adsorption of AL with halides, is endothermic.

\section{Adsorption/thermodynamic studies}

Adsorption characteristics of an inhibitor can be studied using adsorption isotherm. Several adsorption isotherms have been defined for various inhibitors including Temkin, Langmuir, Flory-Huggins, Frumkin and Freundlich adsorption isotherms [25]. Values obtained for the degree of surface coverage of the inhibitor (including combinations of $\mathrm{AL}$ gum and halides) at various temperatures and concentrations were used to fit curves for different adsorption isotherms. The test revealed that the best adsorption isotherm that describes the adsorption characteristics of $\mathrm{Al}$ gum is the Langmuir adsorption isotherm, which can be expressed as follows [26],

$$
\mathrm{bC}=\theta /(1-\theta)
$$

where $b$ is the equilibrium constant of adsorption and is related to the standard Gibb free energy of adsorption $\left(\Delta \mathrm{G}_{\mathrm{ads}}\right)$ according to the following equation,

$$
b=\frac{1}{55.5} \exp \left(\frac{-\Delta G_{a d s}}{R T}\right)
$$

where $\mathrm{R}$ is the universal gas constant, $\mathrm{T}$ is the absolute temperature and 55.5 is the concentration of water in solution $\left(\mathrm{molL}^{-1}\right)$. Simplification of equation 9 yields equation 10 and from the logarithm of both side of equation 10, equation 11 was obtained

$$
\begin{aligned}
& C / \theta=1 / b+C \\
& \log (C / \theta)=\log C-\log b
\end{aligned}
$$

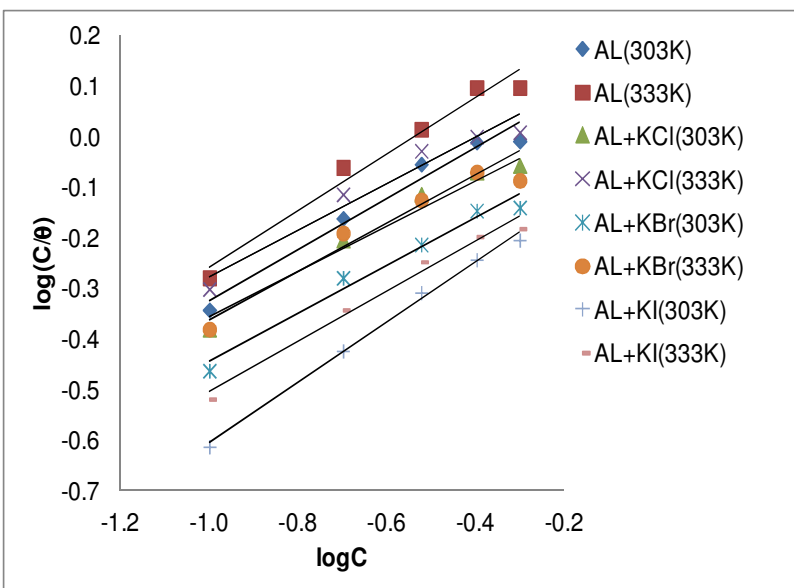

Figure 5. Langmuir adsorption isotherm for of AL gum and for joint adsorption of AL gum with $\mathrm{KI}, \mathrm{KCl}$ and $\mathrm{KBr}$ at 303 and $333 \mathrm{~K}$. 
Table 4. Langmuir adsorption parameters for adsorption of AL gum and co-adsorption of AL gum with halides.

\begin{tabular}{ccccc}
\hline System & logb & $\mathbf{b}$ & $\Delta \mathbf{G}_{\text {ads }}(\mathbf{k J} / \mathbf{m o l})$ & $\mathbf{R}^{2}$ \\
\hline AL+0.05 M KI at 303 K & -0.0104 & 0.9897 & -10.10 & 0.9957 \\
AL+0.05 M KI at 333 K & -0.0069 & 0.9931 & -11.11 & 0.9813 \\
AL+0.05 M KBr at 303 K & 0.0288 & 1.0292 & -10.20 & 0.9749 \\
AL+0.05 M KBr at 333 K & 0.0881 & 1.0921 & -11.37 & 0.9375 \\
AL+0.05 M KCl at 303 K & 0.1137 & 1.1204 & -10.41 & 0.9751 \\
AL+0.05 M KCl at 333 K & 0.1797 & 1.1969 & -11.62 & 0.9503 \\
AL at 303 K & 0.1781 & 1.1949 & -10.57 & 0.9654 \\
AL at 333 K & 0.2983 & 1.3476 & -11.95 & 0.9698 \\
\hline
\end{tabular}

From equation 11, a plot of $\log (\mathrm{C} / \theta)$ versus $\log \mathrm{C}$ should be expected to give a straight line with intercept equal to $-\operatorname{logb}$. Fig. 5 presents the Langmuir adsorption isotherm for AL gum and for co-adsorption of AL gum -halides mixture. Values of Langmuir parameters obtained from the plots are presented in Table 4 . The results reveal that $\mathrm{R}^{2}$ values are very close to unity, which indicates that the adsorption of AL gum and co-adsorption of $\mathrm{AL}$ gum-halide mixtures obeyed the Langmuir adsorption model. ' $b$ ' value indicates the strength of adsorption. The higher the value of ' $b$ ', the better is the adsorption. Recorded values of ' $b$ ' were deduced from the intercepts of the Langmuir plots for the various systems, and by substitution into equation 9, the free energy associated with the adsorption of the inhibitor was also computed (Table 4). The free energies are negatively less than the threshold value of $-40 \mathrm{~kJ} / \mathrm{mol}$ expected for the mechanism of chemical adsorption; therefore, the adsorption of AL gum and co-adsorption of $\mathrm{AL}$ gum with $\mathrm{KI}, \mathrm{KCl}$ and $\mathrm{KBr}$ is spontaneous and supports the mechanism of physical adsorption.

\section{Conclusions}

The findings of the present study indicate that the inhibition efficiency of AL gum can be improved through co-adsorption with $\mathrm{KI}$ and $\mathrm{KBr}$. However, critical concentrations of AL gum that allowed for the synergism with the halides are 0.5 $\mathrm{g} / \mathrm{L}$ and $0.4 \mathrm{~g} / \mathrm{L}$ for $\mathrm{KBr}$ and $\mathrm{KI}$, respectively. The adsorption of $\mathrm{Al}$ gum and coadsorption of the gum with the halides is consistent with the mechanism of physical adsorption. The adsorption is also spontaneous and can best be described by the Langmuir adsorption model.

\section{References}

1. Ameh PO, Magaji L, Salihu T. Afri J Pure Appl Chem. 2012;6(7):100 -106.

2. Acharya S, Upadhyay SN. Trans Indian Inst Metals. 2004;57(3):297-306.

3. Eddy NO, Odoemelam SA, Odiongenyi AO. Green Chemistry Letter Rev. 2009;2(2):111-119.

4. Ebenso EE, Ibok UJ, Ekpe UJ, Umoren S, Abiola OK, Oforka NC, Martinez S. Trans SAEST. 2004;39(4):117-123. 
5. Ebenso EE, Okafor PC, Ibok UJ, Ekpe UJ, Onuchukwu AI. J Chem Soc Nigeria. 2004;29(2):15-25.

6. Elayyoubi SB, Hammouti S, Kertit HO, Maarouf EB. Rev Met Paris. 2004;2:153-157.

7. Acharya S, Upadhyay SN. Trans Indian Inst Metals. 2004;57(3):297-306.

8. Ita BI. Proceedings of the Chemical Society of Nigeria;2004.

9. Ita BI. Bulletin Electrochem. 2004;20(8):363-370.

10. Ita BI. Bulletin Electrochem. 2005;21(7):219-323.

11. Ita BI, Offiong OE. Mater Chem Phys. 1997;51:203-210.

12. Khavasfar A, Iran M. Paper of the $5^{\text {th }}$ International Surface Engineering Congress; 2006 May 16. Seattle, Washington.

13. Rajendran S, Joany MR, Apparao BV, Palaniswamy N. Trans SAEST. 2000;35(3,4):113-117.

14. Zuchi F, Trabanelli G, Gullari G. Electrochem Mater. 1978;34:407-419.

15. Eddy NO, Ameh $\mathrm{P}$, Gimba $\mathrm{CE}$, Ebenso EE. Int J Electrochem Sci. 2011;6:5815-5829.

16. Ameh PO, Gimba CE, Eddy NO, Ebenso EE. Int J Electrochem Sci. 2012;7. In press.

17. S. Rajendran, M. Sivakumar, R. Subadevi, M. Nirmala, Physica B 2004;348:73-78.

18. Eddy NO, Ebenso EE, Ibok UJ. J Appl Electrochem. 2010;40:445-456.

19. Li SL, Wang YG, Chen SH, Yu R, Lei SB, Ma HY, Liu DX. Corr Sci. 1999;41:1273-1287.

20. Eddy NO, Odoemelam SA, Odiongenyi AO, J Appl Electrochem. 2009;39(6):849-857.

21. Umoren SA, Ebenso EE. Pigment Resin Tech. 2008;37(3):173-182.

22. Umoren SA, Obot IB, Ebenso EE. Electronic J Chem. 2008;5(2):355-364.

23. Okafor PC, Zheng Y. Corr Sci. 2009;51:850-859.

24. Eddy NO. J Adv Research. 2010;2:35-47.

25. Eddy NO, Ita BI. Int J Quantum Chem. 2011;111(14):3456-3473.

26. Mohana KN, Badiea AM. Corr Sci. 2008;50:2939-2947. 